Изв. АН Эстонии. Геол., 1991, 40, № 1, 24-32

УДК $550.36(474.5)$

Геннадий УРБАН

\title{
НОВЫЕ ОПРЕДЕЛЕНИЯ ТЕПЛОВОГО ПОТОКА В ПРЕДЕЛАХ ТЕПЛОВОЙ АНОМАЛИИ БАЛТИЙСКОЙ СИНЕКЛИЗЫ
}

Геотермические исследования, проводимые на континентах, показывают, что наиболее низкие тепловые потоки (от 34 до $50 \mathrm{mBT} / \mathrm{m}^{2}$ ) наблюдаются на древних платформах (Кутас, 1978). Для Восточно-Европейской платформы средняя его величина составляет 46 мВт/м ${ }^{2}$ (Комплексное геофизическое изучение..., 1983). Однако и здесь существуют значительные пространства, соответствующие синеклизам, с аномально повышенным тепловым полем. К ним относится, как показывают исследования последних лет, и Балтийская синеклиза, где плотность потока в центральной части достигает 70 м Вт/м², а в отдельных местах превышает и эти значения (Карта теплового потока ..., 1987; Цыбуля, Урбан, 1988). Указанная аномалия установлена на основании измерений теплового потока лишь в нескольких пунктах, и поэтому, чтобы изучить структуру ее поля, а также уточнить положение границ, необходимы были дальнейшие работы.

Все рассматриваемые скважины, в которых проводились измерения температур и изучение теплофизических свойств горных пород, достигают кристаллического фундамента. Это позволило определять тепловой поток в нижней части разреза, сложенного силурийскими, ордовикскими и кембрийскими породами. Для вычисления потока наиболее приемлемы силурийские отложения, поскольку они имеют повсеместное распространение, большую мощность и относительно однородный литологический состав. При бурении скважин керн этих пород, как правило, не отбирался, поэтому их теплофизические свойства определялись по образцам из верхней и нижней частей толщи. Лишь в одной скважине (Гаргждай 8) нанболее детально изучена теплопроводность всего комплекса силурийских образований. Измерение этого параметра осуществлялось стационарным методом на установке $\lambda-400$, а теплофизические характеристики ордовикских и кембрийских пород - зондовым методом (Любимова и др., 1964). Для вычисления средневзвешенной теплопроводности указанных выше стратиграфических подразделений было изучено 150 образцов. Исследования показали, что опубликованные ранее значения теплопроводности силурийских и ордовикских отложений завышены (максимальная погрешность составляет $-0,34$ Вт/м.K). Эта ошибка, особенно при высоких градиентах, привела к завышению теплового потока до 16 мВт/м², поэтому в скважинах Гаргждай 8, Шилале и Клайпеда его величины пересмотрены (Зуй и др., 1985; Цыбуля, Урбан, 1988). В таблице приведены исправленные и новые результаты вычисления потока, а также их класс точности (Смирнов и др., 1974).

Распределение теплового потока в центральной части Балтийской синеклизы представлено на рисунке, который выполнен на основе тектонической схемы кристаллического фундамента Прибалтики (Пуура и др., 1984). Для Западно-Литовского складчатого массива характерны высокие потоки, а для обрамляющих его геологических структур (Рижского плутона, Инчукалнской и Восточно-Литовской складчатых зон) низкие. Этот массив сложен метаморфическими и магматическими породами, сформировавшимися в архейское время (Пуура и др., 1980). К древнейшим интрузивным породам относятся метаморфизованные габбро 
и габбро-нориты, а к метаморфическим - высокоглиноземистые гнейсы, двупироксеновые гнейсы и кристаллические сланцы. Центральная часть массива представлена в основном глиноземистыми гнейсами, а по мере продвижения к его периферическим частям наблюдается их чередование с биотит-амфибол-двупироксеновыми гнейсами и кристаллическими сланцами. По геофизическим данным, в пределах массива выделяется ряд аномалий: мозаичные гравитационные разного знака и полосовые магнитные. Полагают, что древним гранулит-чарнокитовым блокам соответствуют положительные аномалии силы тяжести, а участкам, которые сложены гранито-гнейсами, - отрицательные (Пуура и др., 1984). Тепловой поток здесь изменяется от 54 до 94 мВт/м² (см. рисунок), но преобладает уровень $60-70 \mathrm{mBT} / \mathrm{m}^{2}$. На этом фоне в южной части массива выделяются аномально высокие потоки с максимальной величиной $94 \mathrm{mBт} / \mathrm{m}^{2}$ (скв. Паюрис). K северо-западу располагаются еще две небольшие по площади аномалии: одна из них относительно низких потоков, другая - повышенных. На севере массива, по имеющимся в настоящее время одиночным определениям, значительных отклонений потока от приведенного уровня не установлено.

Ранее отмечалось (Цыбуля, Урбан, 1988), что высокие тепловые потоки наблюдаются там, где в горных породах кристаллического фундамента преобладают глиноземистые гнейсы. Измерения содержания радиоактивных элементов в этих породах показали повышенную их концентрацию, особенно тория. На основе полученных результатов проведена оценка теплогенерации, которая в южной части Западно-Литовского массива составляет $4 \mathrm{mkBт} / \mathrm{m}^{3}$.

Тепловой поток центральной части Балтийской синеклизы. 1 - геологические границы структурных элементов кристаллического фундамента (тектоническая схема нанесена согласно работе Пуура и др., 1984); 2 - основные разломы и зоны разломов: Т - Тельшайский разлом, Т-O - Таурагско-Огрская зона; Ж - Жемайтийская зона; 3 - структурные элементы кристаллического фундамента: II - Западно-Литовский архейский массив, III - Калининградский блок, VIII - Инчукалнская складчатая зона, IX - Восточно-Литовская складчатая зона, 6 - Рижский плутон: а - граниты-рапакиви, б - габбро-нориты и анортозиты; 4 -местоположение скважин: в числителе - номер скважины, в знаменателе - плотность теплового потока, мВт/м²: а - определенные впервые, б - опубликованные ранее; 5 - изолинии теп-

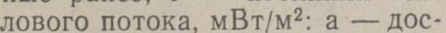
товерные, б - предполагаемые.
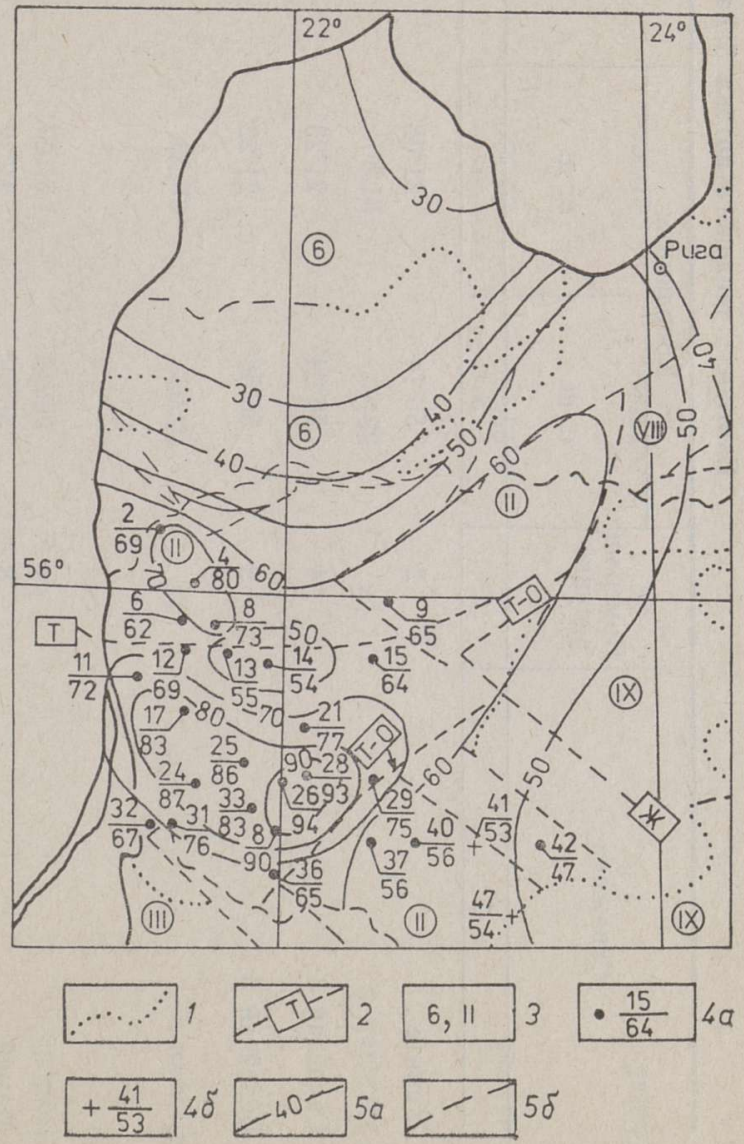


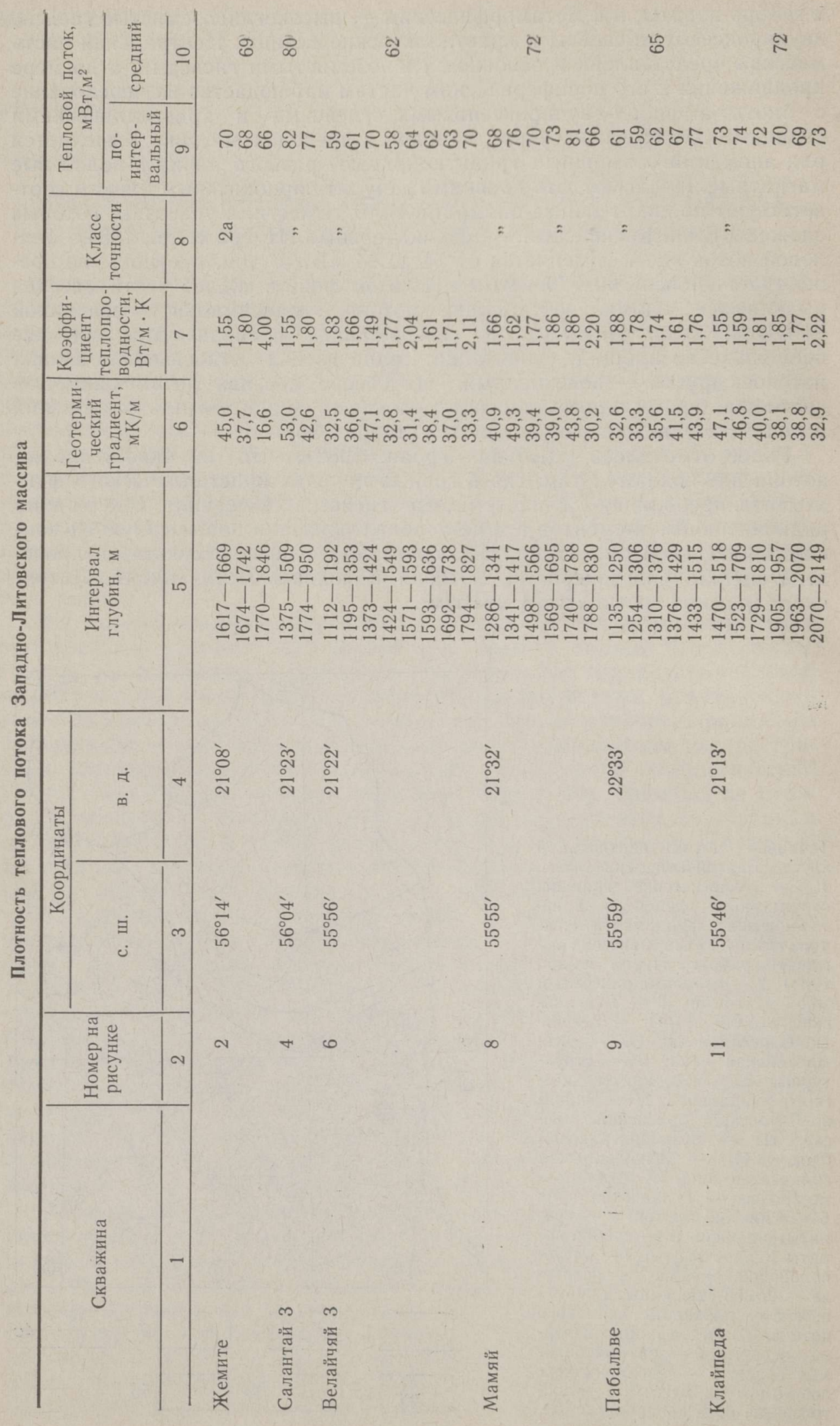




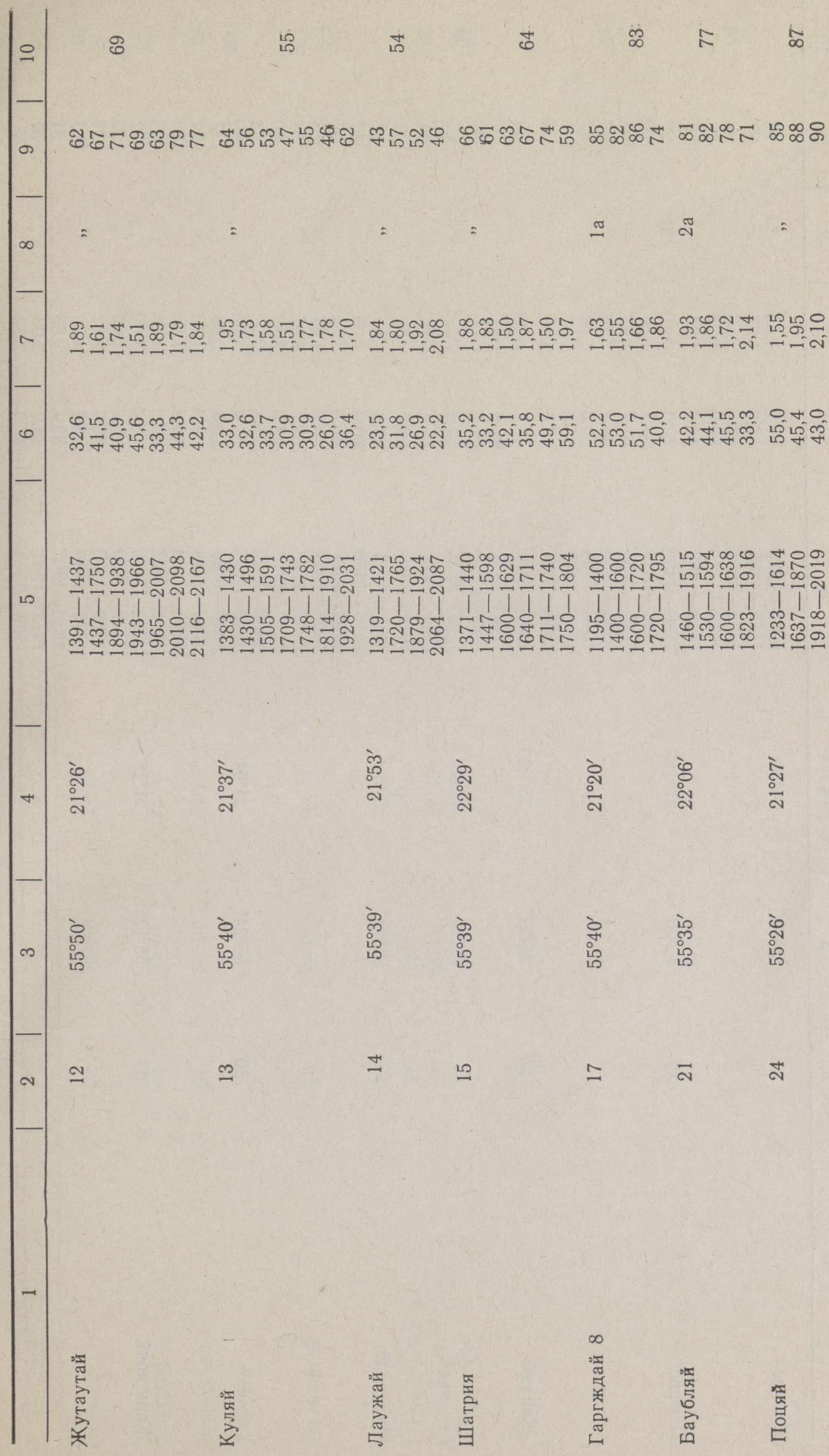




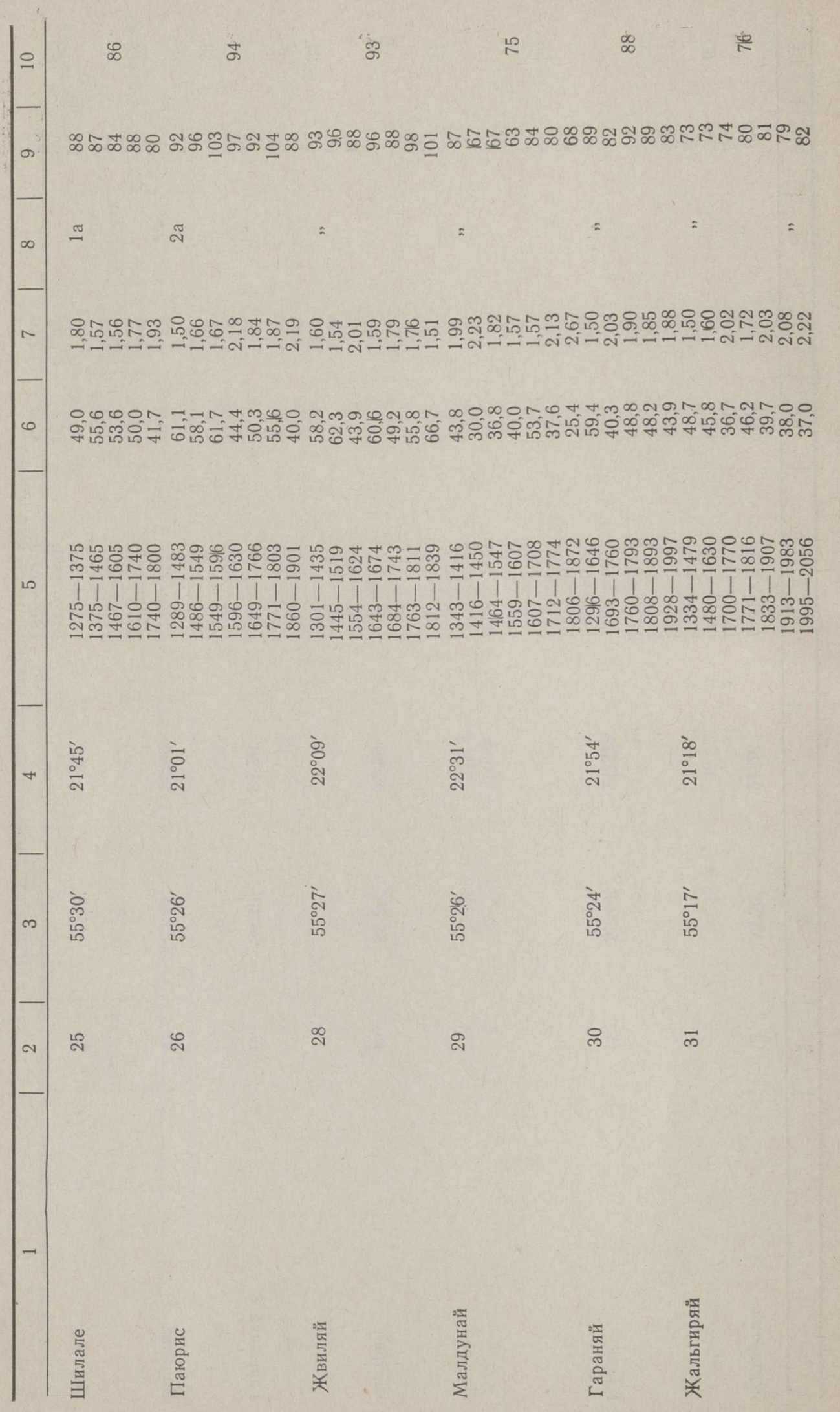


10 เ 8 \& 8 in

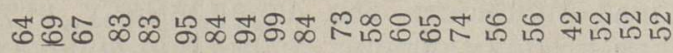

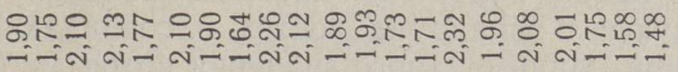

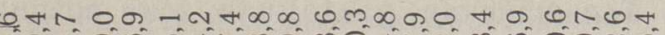

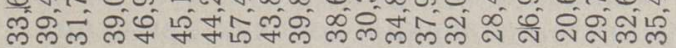

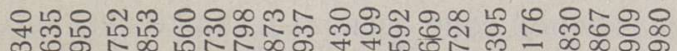

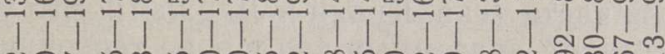

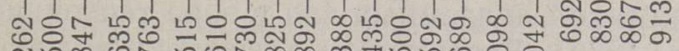

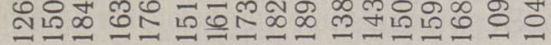

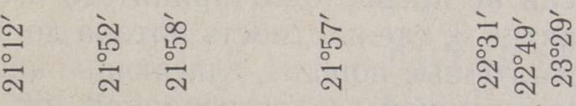

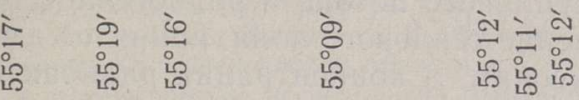

ले ल मे है के श

a

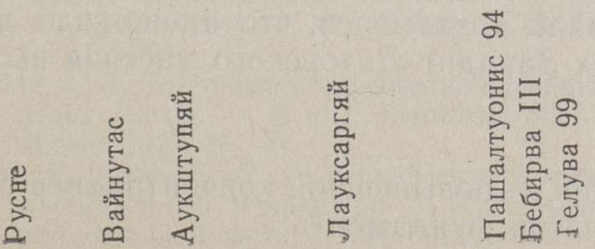


Если считать, что верхняя часть кристаллического фундамента на юге массива сложена, главным образом, гранитами и гранито-гнейсами (что подтверждается присутствием здесь отрицательной гравитационной аномалии) с высоким торий-урановым отношением, то аномальное увеличение потока обусловлено здесь интенсивным тепловыделением из приповерхностного слоя земной коры. Мощность его, по-видимому, незначительна, так как теплогенерация в обрамляющих аномалию породах уже уменьшается более чем в два раза, а тепловой поток ниже только на $10-20 \mathrm{мBт} / \mathrm{m}^{2}$. Например, в Гаргждайской зоне поднятий тепловыделение составляет $2 \mathrm{mkBт} / \mathrm{m}^{3}$, хотя плотность потока практически неизменна $-83 \mathrm{мBт} / \mathrm{m}^{2}$.

Анализируя распределение теплового потока в целом для ЗападноЛитовского массива, можно видеть полосу пониженных значений (от 54 до 72 мВт/ ${ }^{2}$ ), простирающуюся с запада на восток и совпадающую с Тельшайской разломной зоной. Минимального значения поток достигает в центре полосы, где выделяется небольшая по площади аномалия.

Существует мнение, что Тельшайская разломная зона возникла за очень короткое время в результате позднекаледонских движений (Стирпейка, 1977). Следовательно, она должна характеризоваться потоками, не отличающимися от средней величины (65 мВт/м²), так как только долгоживущим разломам, сохранявшим свою активность и в кайнозое, свойственно повышенное тепловое поле. В действительности тепловые потоки в рассматриваемой разломной зоне несколько ниже среднего значения, особенно в центральной части (скв. Куляй и Лаужай). Это уменьшение, видимо, вызвано динамикой подземных вод в зоне тектонических нарушений (Брангулис и др., 1978). Вертикальные перетоки вод из нижних водоносных горизонтов в верхние ведут к перераспределению тепла и «сглаживанию» геотермического градиента.

В северо-западном направлении величина теплового потока вновь возрастает, однако она практически не превосходит принятого среднего уровня, за исключением скв. Салантай 3 , где плотность потока достигает $80 \mathrm{mBт} / \mathrm{M}^{2}$. В районе этой скважины горные породы, слагающие кристаллический фундамент, обладают повышенной теплогенерацией (от 2,5 до $\left.5,0 \mathrm{mkBт} / \mathrm{M}^{3}\right)$, чем и обусловлено увеличение плотности потока.

Таким образом, в пределах Западно-Литовского массива существует прямая связь между величиной теплового потока и радиогенной генерацией тепла. Однако фоновое значение теплового поля, принятое для этой структуры, остается довольно высоким, а концентрация радиоактивных элементов недостаточна, чтобы можно было ею компенсировать тепловыделение, поступающее из земной коры. Содержание урана и тория в породах массива, за исключением аномальных участков, близко к кларковому. Это эквивалентно теплогенерации $0,7-2,8 \mathrm{mkBт} / \mathrm{m}^{3}$, что соответствует породам, образовавшимся в условиях гранулитовой и амфиболитовой фаций (Смыслов и др., 1979). Сопоставляя приведенные данные с данными по другим районам западной части Восточно-Европейской платформы и учитывая имеющиеся представления о распределении радиоактивных элементов в земной коре (Кутас, 1978), можно предположить, что вклад радиогенной составляющей в общий тепловой баланс равен примерно $30-40$ мВт/м². Следовательно, остальная часть потока порядка $30 \mathrm{mBT} / \mathrm{m}^{2}$ поступает из мантии Земли.

Анализ фактического материала показывает, что площадные вариации теплового потока в пределах Западно-Литовского массива вызваны следующими причинами:

1) аномально высокие значения - повышенной концентрацией радиоактивных элементов в верхней части фундамента; 
2) полоса пониженного потока, ориентированная в широтном направлении и совпадающая с Тельшайской разломной зоной, - гидрогеологическими условиями данного района;

3) высокий фоновый тепловой поток, превосходящий в полтора-два раза его величины для обрамляющих структур, - существенным привносом тепла из мантии.

Рассматриваемая тепловая аномалия простирается на юго-запад и охватывает Калининградский блок архейских пород. Здесь величина потока возрастает до 97 мВт/м² (Цыбуля и др., 1984), а среднее значение равно $69 \pm 13$ мВт/м² (Геофизическая модель..., 1987). В акваториальной части Балтийской синеклизы до настоящего времени нет определений теплового потока. С учетом того, что повышенное тепловое поле наблюдается на северо-западном побережье Польши (Майорович, Плева, 1982) и юго-востоке Швеции (Әрикссон, Мальмквист, 1982), предполагается здесь наличие поля высоких тепловых потоков (Урбан, Козел, 1990).

Считается, что положительная аномалия тепловых потоков, расположенная на территории Германии, продолжается в южные районы Швеции (Чермак, 1982; Геофизическая модель..., 1987). Тогда в этом регионе возможно существование единой зоны повышенных потоков, происхождение которой обусловлено интенсивным поступлением тепла из мантии Земли. На активизацию земных недр в пределах акватории Балтийского моря указывает ряд геолого-геофизических исследований. Таким образом, можно думать, что определяющую роль в формировании поля тепловых потоков исследуемой части Балтийской синеклизы играет современная активность тектонических процессов, сходных, возможно, с процессами, протекающими на северо-востоке Германии.

\section{ЛИ Т Е РА Т У Р А}

Брангулис А. П., Брио Х. С., Бендруп Л. Н., Фрейманис А. А., Мурниекс А. Э., Струме Я. А. Влияние тектоники на размещение полезных ископаемых в осадочном чехле Латвии. - В кн.: Тектоника и полезные ископаемые Белоруссии и Прибалтики. Калининград, 1978, 75-83.

Геофизическая модель тектоносферы Европы. Киев, 1987.

Зуй В. И., Урбан Г. И., Веселко А. В., Жук М. С. Геотермические исследования в скважинах Калининградской области и Литовской ССР. - В кн.: Сейсмологические и геотермические исследования в Белоруссии. Минск, 1985, 88-94.

Карта теплового потока Европейской части СССР. Масштаб 1:5000000. Л., 1987.

Комплексное геофизическое изучение тектоносферы континентов. Киев, 1983.

Кутас Р. И. Поле тепловых потоков и термическая модель земной коры. Киев, 1978.

Любимова E. А., Старикова P. Н., Шуипанов А. П. Теплофизические исследования горных пород. - В кн.: Геотермические исследования. М., 1964, 115-174.

Майорович Я., Плева С. Изучение теплового потока в Польше и решение тектонофизических задач. - В кн.: Тепловое поле Европы. М., 1982, 261-276.

Пуура В. А., Биркис А. П., Мотуза Г. Б. Геологическая карта кристаллического фундамента республик Советской Прибалтики. Объяснительная записка. Л., 1980.

Пуура В. А., Биркис А. П., Мотуза Г. Б. Тектоника кристаллического фундамента Прибалтийского региона. - В кн.: Тектонические исследования запада ВосточноЕвропейской платформы. Минск, 1984, 43-56.

Смирнов Я. Б., Безроднов В. Д., Волобуев Г. Л. и др. Глубинный тепловой поток в северной и центральной частях Восточно-Европейской платформы. - В кн.: Глубинный тепловой поток Европейской части СССР. Киев, 1974, 7-46.

Смыслов А. А., Моисеенко У. И., Чадович Т. З. Тепловой режим и радиоактивность Земли. Л., 1979.

Стирпейка А. Д. Тектоническое развитие и районирование Балтийской синеклизы в пределах Литвы. - В кн.: Региональная тектоника Белоруссии и Прибалтики. Минск, 1977, 35-41.

урбан Г. И., Козел В. П. Геотермические условия северной части Западно-Литовского массива и его обрамления. - В кн.: Сейсмические и геотермические исследования западной части СССР. Минск, 1991, (в печати). 
Цыбуля Л. А., Люсева Л. Н., Смирнова Е. В. Тепловой поток в Припятском прогибе и Балтийской синеклизе (Қалининградская область). - В кн.: Методика и результаты геолого-геофизических нефтепоисковых исследований в Припятском прогибе. Минск, 1984, 102-110.

Цыбуля Л. А., Урбан $Г$. И. Тепловое поле Балтийской синеклизы и некоторые аспекты его связи с глубинным строением земной коры. - В кн.: Комплексные исследования глубинного строения территории Белоруссии и смежных областей. Минск, 1988, 28-34.

Чермак В. Карта теплового поля Европы. - В кн.: Тепловое поле Европы. М., 1982, $11-54$.

Эрикссон К. Г., Мальмквист Д. Обзор прошлых и современных исследований теплового потока в Швеции. - В кн.: Тепловое поле Европы. М., 1982, 353-365.

Ннститут геохимии и геофизики Академии наук Белорусской ССР
Поступила в редакцию $31 / \mathrm{X} 1989$

\section{Gennadi URBAN}

\section{UUSI SOOJUSVOO MÄARANGUID BALTI SUNEKLIISI SOOJUSANOMAALIA PIIRES}

On esitatud Balti sünekliisi keskosa geotermiline iseloomustus ning selgitatud, et aluskorra Lääne-Leedu massiivi piires on soojusvoog kōrgem tavalisest ja moodustab $54-94 \mathrm{mWt} / \mathrm{m}^{2}$. Keskmise väärtuse $\left(65 \mathrm{mWt} / \mathrm{m}^{2}\right)$ taustal eristub mitmeid väikese pindalaga anomaaliaid, mida võib seostada mõnede aluskorrakivimite võimega genereerida rohkem radiogeenset soojust, aga ka piirkonna hüdrogeoloogiliste iseärasustega. On oletatud, et Lääne-Leedu ja Kaliningradi oblasti alal esinev soojusanomaalia levib ka Läänemere põhjakivimites ning on sealtkaudu ühenduses Saksamaa aladel teadaoleva positiivse soojusanomaaliaga. Väidetavalt on sellise ulatusliku anomaalia põhjustanud Maa vahevööst eralduv anomaalne soojusvoog.

\section{Gennadi URBAN}

\section{NEW EVIDENCE IN MEASURING HEAT FLOW IN THE REGION OF HEAT ANOMALY OF THE BALTIC SYNECLINE}

A geotermic characterization of the central part of the Baltic synecline is presented. It appears that in the basement of the massif of West Lithuania, heat flow is higher than normal, namely 54 to $94 \mathrm{mWt} / \mathrm{m}^{2}$. There occur several small-size anomalies in this region which may be explained by the ability of the basement rock to generate more radiogenic heat, and also by the hydrogeological peculiarities of the region. It is presumed that the heat anomaly occurring in West Lithuania and the Kaliningrad Region extends to the basement rock of the Baltic Sea and is connected with the positive heat anomaly noted in Germany. It is suggested that such a wide spread of the anomaly may be the result of anomalic heat emission from the Earth's mantle. 